\title{
Development of an algorithm for forecasting and preventing emergency situations in industrial traffic control systems based on data analysis of multi-code labels
}

\author{
A V Astafiev ${ }^{1}$, A A Orlov ${ }^{1}$ and T O Shardin ${ }^{1}$ \\ ${ }^{1}$ Vladimir State University, Gorkij str. 87, Vladimir, Russia, 600000
}

\begin{abstract}
This article proposes a method for controlling the movement of industrial products based on data from multi-code labels using the algorithm for forecasting and preventing extraordinary situations. In the course of the work, possible extraordinary situations arising in the process of displacement were analyzed. Also on the basis of the developed algorithms, simulation modeling was carried out, according to the results of which it was shown the effective use of this method for controlling the movement of products in industrial enterprises.
\end{abstract}

\section{Introduction}

At present, for the identification of industrial products, product marking is mainly used with the help of barcode [1] or radio frequency tags [7-10]. These solutions do allow you to shorten the time of searching for a product on the territory of the enterprise, however, they are not without shortcomings, since they are not able to forecast possible supernumerary situations.

For example, when moving a load, the label is not always in the sensor's field of view, so that the marking is not visible to the reader or person. Although it is worth noting that for security reasons, people in such jobs are practically not involved. Also, the marking, during transport or movement on the conveyor belt, may be poorly secured, as a result, it may fall off or fall onto another product. Proceeding from this, it can be concluded that for reliable product identification, several markings on one product should be used, the number of which can depend on the geometric parameters of the object. To accurately control the location of products, you should use the algorithm for finding errors in the occurrence of abnormal situations (for example: when several labels identify one label from several possible ones), which will promptly make a decision to the operator and eliminate the violation.

The purpose of this work is the development of an algorithm for forecasting and preventing emergency situations in traffic control systems for industrial products based on the analysis of data of multi-code labels, during which it is necessary to perform the following tasks:

- conduct a comparative analysis of analogue systems;

- develop a simulation model of the process of moving products;

- to formulate freelance situations;

- develop an algorithm for forecasting and preventing extraordinary situations;

- carry out an experimental study using simulation tools. 


\section{Overview of analogues}

At the moment, to implement the goal, there are several similar solutions. We will perform a comparative analysis of these analogs, as a result of which we can conclude which system is more profitable to use in the future:

1. VITRONIC - automatic recognition system is used to read barcodes in various industries. The results of a comparative analysis of this system are given in Table 1:

Table 1. Advantages and disadvantages of using VITRONIC.

\begin{tabular}{c}
\hline \multicolumn{2}{c}{ VITRONIC } \\
\hline $\begin{array}{c}\text { Advantages of use } \\
\text { 2D) }\end{array}$ \\
$\begin{array}{c}\text { Decognition of different types of codes (1D, } \\
\text { Reading OCR (serial numbers, batch numbers, } \\
\text { articles, etc.) } \\
\text { Multi-code reading }\end{array}$ \\
$\begin{array}{c}\text { Thentation of an algorithm for monitoring } \\
\text { contingencies is required }\end{array}$ \\
\hline
\end{tabular}

3. OptiCode is an industrial scanner for high-speed barcode reading. Advantages and disadvantages are presented in Table 2:

Table 2. Advantages and disadvantages of using OptiCode.

\begin{tabular}{cc}
\hline & OptiCode \\
\hline $\begin{array}{c}\text { Advantages of use } \\
\begin{array}{c}\text { Tracking the product from the moment of } \\
\text { receipt to the warehouse }\end{array}\end{array}$ & $\begin{array}{c}\text { Disadvantages of use } \\
\text { The implementation of an algorithm for monitoring } \\
\text { contingencies is required }\end{array}$
\end{tabular}

anning barcodes from a long distance $(15 \mathrm{~m})$

Allows you to position the camera on cranes or

carts

No multi-code reading support

As a result of the comparative analysis of the presented analogs, it can be concluded that these solutions are not entirely suitable for use, since they basically do not have an algorithm for forecasting and preventing contingencies. In some cases, there is no support for multi-code reading, as a result of which a significant amount of funds will be required for the development, which is unprofitable.

\section{Development of a simulation model for the movement of industrial products}

At the enterprise every $100 \pm 2 \mathrm{~s}$ there are applications for receiving products. Then the products are moved to storage racks. Processing of such applications takes $180 \pm 2 \mathrm{~s}$. After the work can move to the neighbouring shelves or the place of shipment. The processing takes $150 \pm 2 \mathrm{~s}$ and $160 \pm 4 \mathrm{~s}$, respectively. In the case of accepting applications for participation or the remaining applications do not have time to process within a specified period of time, they are automatically lost. It is required to simulate the work by moving industrial goods during one working shift. The scheme of this simulation model is shown in Figure 1.

It should be noted that during the operation of the simulation model, the following contingencies may arise during the transportation of products, which must be taken into account:

1. Supernumerary situation 1 - during the movement of the product, the same marking is read.

2. Supernumerary situation 2 - in the process of identification, a non-existent marking fell into the field of view of the reader.

3. Supernumerary situation 3 - During the transfer to the product, the marking of another object, by mechanical action (marking off) or deliberate action of personnel (intentional re-gluing of the marking) fell on the product.

\section{Development of an algorithm for forecasting and preventing emergency situations during the movement of products}

Consider the algorithm for predicting and preventing emergency situations by steps: 


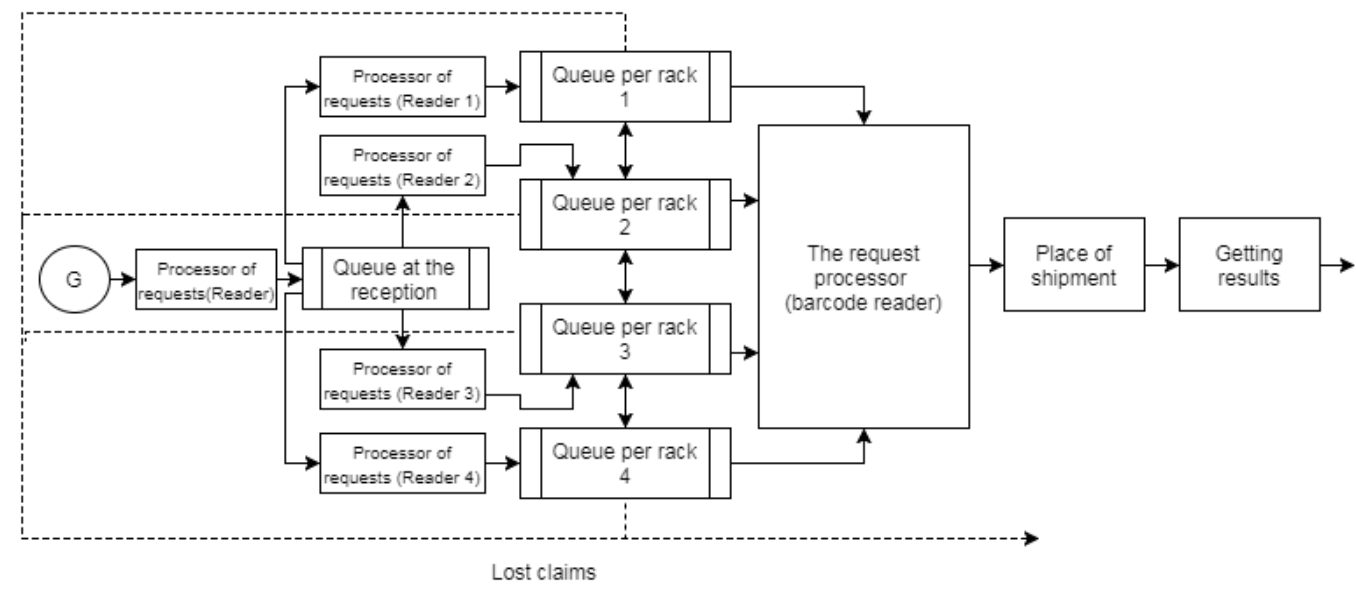

Figure 1. Model outline.

1. When goods arrive at the place of reception, we fix the identified product markings, the time of arrival, and its location.

2. When moving, the time, the current location and location of the rack, to which the product enters, is fixed.

3. Receipt on the rack is the same as in paragraph 1 with the comparison of marks.

4. Moving between the shelves and when entering the place of shipment occurs, in accordance with paragraphs 1-3.

5. If during the movement of the product from the storage areas the same marking is received in the field of view of the reader, the system generates a warning for its verification, which corresponds to an abnormal situation 1 .

6. If a non-existent marking has appeared in the field of view of the reader or from another product, we generate a warning, which corresponds to abnormal situations 2,3 .

The flowchart of the algorithm is shown in Figure 2:

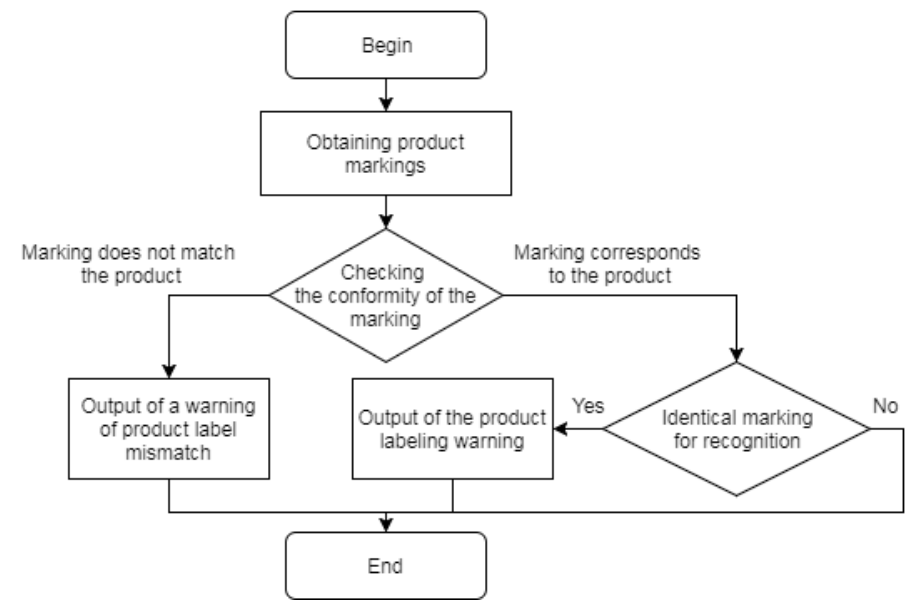

Figure 2. Block diagram of the algorithm being developed.

\section{Experimental study with barcodes}

\subsection{Description of the experiment}

Before the implementation of the algorithm and model, an experiment was conducted to collect all the necessary input data.

The experiment consisted of the following:

1. We took an object of a cylindrical shape, placed on it 4 barcodes. There can be several items, since in real production when moving products with a crane or a conveyor belt, several products are simultaneously received in the field of the reading sensor. 
2. With the help of any technical device that allows you to capture an image (for example: a mobile phone camera or a camera), you took a few pictures, on which the products were imaged in different positions (different positions are meant).

3. On the basis of the collected images, a representative sample of the read barcodes was made and all the data entered into the table.

4. As a result of the collected information, the probability of identified markings was calculated, which later allowed modeling and implementing the necessary algorithms:

\subsection{Image analysis}

During the experiment, 3 cylindrical objects were taken, on each of which 4 barcodes were attached. For multi-code labeling, a Code-11 bar code was used, as shown in Figure 3:

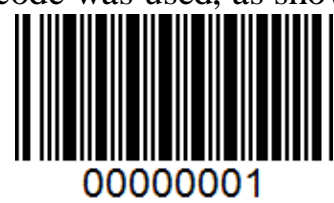

Figure 3. Example barcode used for marking products.

In order to get a more accurate result, you need to photograph as many different cases as possible. The result is shown in Figure 4:
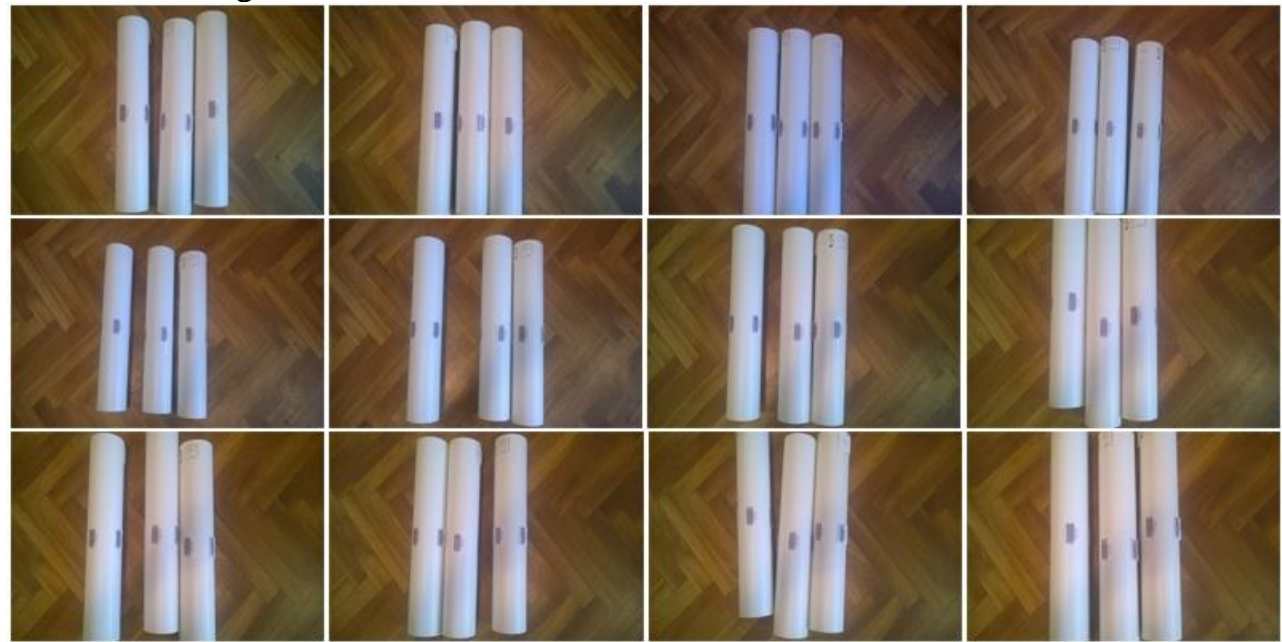

Figure 4. Example of images taken during shooting.

As can be seen from Figure 4, with different positioning of the object, in most cases 1 or 2 barcodes are identified. It is worth noting that on some images, there were recognized 3 marks on one product, but this result is extremely rare and can be neglected, since the label is practically not visible. Based on the images received, a sample was taken, the results of which are summarized in Table 3:

Table 3. Total number of identified labels.

\begin{tabular}{|c|c|c|c|c|c|c|c|c|c|c|c|c|c|}
\hline \multirow{4}{*}{$\begin{array}{l}\text { Imag } \\
\text { e No. }\end{array}$} & \multicolumn{12}{|c|}{ Number of identified barcodes } & \multirow{3}{*}{$\begin{array}{c}\text { Unreco } \\
\text { gnized } \\
\text { barcod } \\
\text { es }\end{array}$} \\
\hline & \multicolumn{4}{|c|}{$\begin{array}{c}\text { Pipe } 1 \\
\text { Barcode number on the pipe }\end{array}$} & \multicolumn{4}{|c|}{$\begin{array}{c}\text { Pipe } 2 \\
\text { Barcode number on the pine }\end{array}$} & \multicolumn{4}{|c|}{$\begin{array}{c}\text { Pipe } 3 \\
\text { Barcode number on the pipe }\end{array}$} & \\
\hline & 0000 & 0000 & 0000 & 0000 & 0000 & 0000 & 0000 & 0000 & 0000 & 0000 & 0000 & 0000 & \\
\hline & 0001 & 0002 & 0003 & 0004 & 0005 & 0006 & 0007 & 0008 & 0009 & 0010 & 0011 & 0012 & \\
\hline 1 & & & & 1 & & & 1 & 1 & & & 1 & & 1 \\
\hline 2 & 1 & & & & 1 & & & 1 & & & 1 & & 0 \\
\hline 3 & 1 & & & 1 & & & 1 & 1 & & & 1 & 1 & 0 \\
\hline 4 & & & & 1 & & & 1 & & & & & 1 & 2 \\
\hline 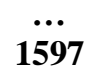 & $\ldots$ & $\ldots$ & 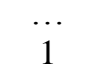 & & $\ldots$ & & 1 & $\dddot{1}$ & & & $\dddot{1}$ & & 1 \\
\hline
\end{tabular}




\begin{tabular}{|c|c|c|c|c|c|c|c|c|c|c|c|c|c|}
\hline 1598 & & & 1 & & & & 1 & & & & 1 & 1 & 1 \\
\hline 1599 & 1 & & & 1 & & & & 1 & 1 & & & & 2 \\
\hline 1600 & & 1 & & & & & 1 & & & & 1 & & 1 \\
\hline $\begin{array}{c}\text { Total } \\
\text { Recog } \\
\text { nized }\end{array}$ & 680 & 240 & 280 & 720 & 80 & 80 & 760 & 760 & 720 & 280 & 400 & 320 & 1840 \\
\hline Total & \multicolumn{4}{|c|}{1920} & \multicolumn{4}{|c|}{1680} & \multicolumn{4}{|c|}{1720} & 1840 \\
\hline
\end{tabular}

According to the information presented in Table 3, you can find out the numeric data on the recognition of only 1 barcode, 2 or more:

Table 4. Number of read tags on each object.

\begin{tabular}{cccc}
\hline Option & \multicolumn{3}{c}{ Number of read tags } \\
\cline { 2 - 4 } 1 barcode recognized & Pipe 1 & Pipe 2 & Pipe 3 \\
2 barcodes & 620 & 960 & 1020 \\
$\begin{array}{c}\text { recognized } \\
\text { or more barcodes } \\
\text { recognized }\end{array}$ & 0 & 640 & 580 \\
\hline
\end{tabular}

As a result, from the presented tables it is possible to calculate the probability of barcode identification on the product:

1. Probability of recognition of 1 barcode: $66,67 \%$

2. The probability of recognizing 2 barcodes: $33.33 \%$

\section{Experimental study with RFID technology}

\subsection{Description of the experiment}

This experiment allowed us to determine the angle at which RFID readers should be installed for optimal recognition for different forms of products.

The experiment consisted of the following:

1. We took a cylindrical object.

2. Was pasted with RFID tags from different sides.

3. Next, the object was placed arbitrarily on a flat surface.

4. Using RFID reader determined how many labels are considered at a certain angle, namely: at an angle of 0 degrees, 45 degrees (vertical), and $45+45$ degrees (vertical and horizontal), for two seconds.

5 . The obtained data were entered in tables for further plotting.

\subsection{Results of the experiment}

Figure 5 shows the process of reading RFID tags by the reader:
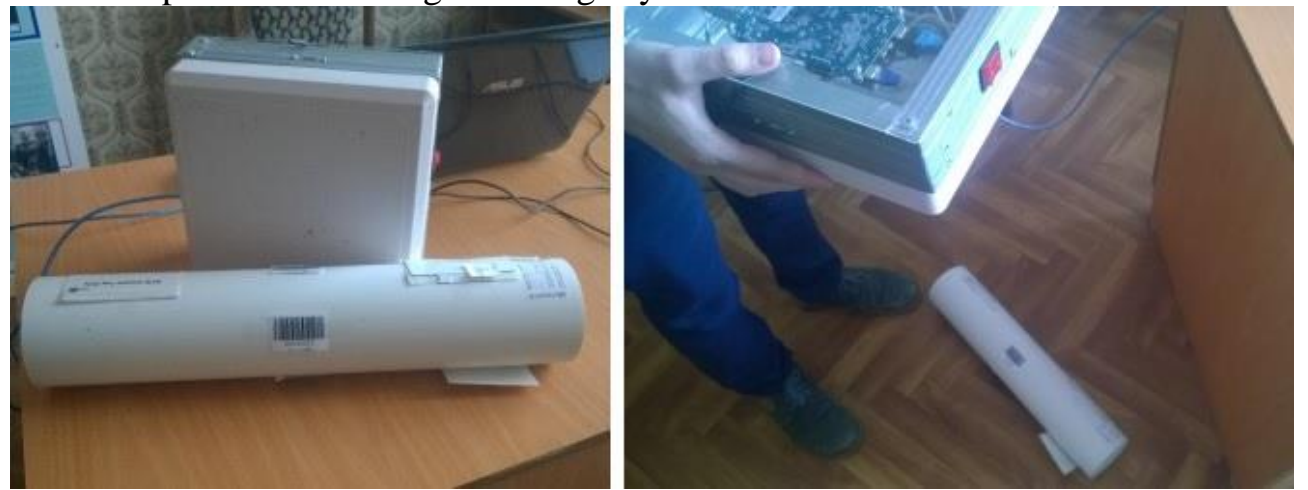

Figure 5. The process of reading RFID tags by the reader. 
The data of the read marks from the cylindrical object are shown in table 5:

Table 5. Number of read RFID tags.

\begin{tabular}{|c|c|c|c|c|c|c|c|c|c|}
\hline \multirow[t]{2}{*}{ № } & \multirow[t]{2}{*}{ Angle } & \multicolumn{2}{|c|}{ Label 1} & \multicolumn{2}{|c|}{ Label 2} & \multicolumn{2}{|c|}{ Label 3} & \multicolumn{2}{|c|}{ Label 4} \\
\hline & & Count & RSSI & Count & RSSI & Count & RSSI & Count & RSSI \\
\hline 1 & 0 & 13 & 54 & 10 & 55 & 8 & 56 & 10 & 66 \\
\hline 2 & & 5 & 60 & 3 & 53 & 7 & 61 & 6 & 59 \\
\hline 3 & & 4 & 61 & 6 & 51 & 4 & 55 & 7 & 58 \\
\hline 4 & & 5 & 52 & 8 & 48 & 4 & 56 & 4 & 59 \\
\hline 5 & & 3 & 58 & 6 & 62 & 7 & 60 & 5 & 59 \\
\hline & & 4 & 55 & 7 & 58 & 7 & 55 & 3 & 60 \\
\hline 97 & & 2 & 69 & 13 & 52 & 13 & 58 & 13 & 61 \\
\hline 98 & & 4 & 58 & 6 & 59 & 6 & 55 & 5 & 65 \\
\hline 99 & & 6 & 57 & 7 & 58 & 5 & 56 & 3 & 64 \\
\hline 100 & & 6 & 54 & 7 & 55 & 3 & 67 & 5 & 60 \\
\hline 1 & 45 & 5 & 63 & 5 & 58 & 7 & 57 & 4 & 64 \\
\hline 2 & & 5 & 53 & 4 & 55 & 5 & 66 & 7 & 54 \\
\hline 3 & & 5 & 61 & 6 & 49 & 5 & 66 & 5 & 53 \\
\hline 4 & & 6 & 59 & 5 & 54 & 6 & 64 & 4 & 55 \\
\hline 5 & & 7 & 58 & 6 & 52 & 4 & 68 & 4 & 64 \\
\hline .. & & 4 & 64 & 7 & 57 & 3 & 62 & 7 & 57 \\
\hline 97 & & 6 & 58 & 6 & 58 & 9 & 54 & 0 & 0 \\
\hline 98 & & 6 & 56 & 6 & 57 & 9 & 56 & 0 & 0 \\
\hline 99 & & 3 & 64 & 8 & 51 & 4 & 56 & 6 & 60 \\
\hline 100 & & 5 & 56 & 2 & 51 & 7 & 55 & 7 & 56 \\
\hline 1 & $45+45$ & 4 & 61 & 5 & 55 & 7 & 59 & 5 & 62 \\
\hline 2 & & 6 & 54 & 6 & 56 & 4 & 66 & 5 & 60 \\
\hline 3 & & 6 & 64 & 4 & 64 & 6 & 64 & 5 & 61 \\
\hline 4 & & 4 & 52 & 7 & 59 & 5 & 59 & 5 & 59 \\
\hline 5 & & 5 & 51 & 6 & 51 & 6 & 58 & 4 & 64 \\
\hline & & 11 & 50 & 11 & 47 & 10 & 55 & 9 & 72 \\
\hline 97 & & 6 & 49 & 6 & 50 & 5 & 61 & 4 & 63 \\
\hline 98 & & 5 & 52 & 8 & 54 & 6 & 71 & 2 & 59 \\
\hline 99 & & 10 & 61 & 11 & 57 & 9 & 58 & 11 & 58 \\
\hline 100 & & 8 & 59 & 11 & 56 & 12 & 67 & 10 & 61 \\
\hline
\end{tabular}

According to the information presented in table 5, you can find the average number of each read mark, depending on the position of the RFID reader:

Table 6. Average number of tags read.

\begin{tabular}{ccccc}
\hline \multicolumn{5}{c}{ Average number of tags read } \\
\hline Angle & Label 1 & Label 2 & Label 3 & Label 4 \\
0 & 5 & 7 & 6 & 6 \\
45 & 5 & 5 & 6 & 4 \\
$45+45$ & 9 & 8 & 10 & 12 \\
\hline
\end{tabular}

According to the results presented in tables 5, 6, you can see that the read marks are most observed at an angle of $45+45$ degrees (vertical and horizontal), since the sensor field of view is increased, it allows you to capture more marks than in other versions of its RFID reader placement.

\section{Results of the simulation model work}

Based on the scheme of the developed simulation model, presented in Figure 1, it can be seen that each movement of the object is controlled by reading the markings with the help of the handler of applications from the place of receipt of the product to its shipment. In this handler there is a comparison of the markings and further decision-making on the output of messages in the event of abnormal situations during transportation (Figure 6,7): 


\begin{tabular}{|c|c|c|c|}
\hline \multicolumn{4}{|c|}{ The process of moving: } \\
\hline $10: 00: 57$ & Product ID: 6 Moved to the rack 4 | & Recognized: 9880750,9880748 & $\Delta$ \\
\hline $10: 00: 57$ & Product ID: 2 Moved to the place of & shipment | Recognized: 1922516,1922517 & \\
\hline $10: 00: 58$ & Product ID: 11 Moved to the rack 3 & Recognized: 9441368,9441369 & \\
\hline $10: 00: 58$ & Product ID: 6 Moved to the place of & shipment | Recognized: 9880749 & \\
\hline $10: 00: 59$ & Product ID: 21 Moved to the rack 1 & Recognized: 2055596 & \\
\hline $10: 01: 00$ & Product ID: 11 Moved to the place of & shipment | Recognized: 9441368,9441369 & \\
\hline $10: 01: 00$ & Product ID: 22 Moved to the rack 4 & Recognized: 9860738 & \\
\hline $10: 01: 01$ & Product ID: 30 Moved to the rack 4 & Recognized: 9429826,9429825 & \\
\hline $10: 01: 01$ & Product ID: 35 Moved to the rack 4 & Recognized: 6378369 & \\
\hline $10: 01: 02$ & Product ID: 21 Moved to the place of & shipment | Recognized: 2055596 & \\
\hline $10: 01: 05$ & Product ID: 64 Moved to the rack 1 & Recognized: 7303325,7303324 & \\
\hline $10: 01: 06$ & Product ID: 46 Moved to the rack 1 & Recognized: 1054826 & \\
\hline $10: 01: 06$ & Product ID: 35 Moved to the place of & shipment | Recognized: 6378372 & \\
\hline $10: 01: 06$ & Product ID: 30 Moved to the place of & Recognized: 9429824 & \\
\hline $10: 01: 07$ & Product ID: 45 Moved to the rack 4 & Recognized: 6363338,6363335 & \\
\hline $10: 01: 08$ & Product ID: 60 Moved to the rack 1 & Recognized: 9979266 & \\
\hline $10: 01: 09$ & Product ID: 20 Moved to the rack 2 & Recognized: 7325444,7325445 & 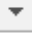 \\
\hline
\end{tabular}

Figure 6. Displaying the progress report.

\begin{tabular}{|c|c|c|}
\hline \multicolumn{3}{|c|}{ Displaying system messages: } \\
\hline $10: 00: 57$ & Product ID: 4 & Check is not required \\
\hline $10: 00: 57$ & Product ID: 5 & Check marking \\
\hline $10: 00: 57$ & Product ID: 2 & Check is not required \\
\hline $10: 00: 58$ & Product ID: 6 & Check is not required \\
\hline $10: 01: 00$ & Product ID: 11 & Check is not required \\
\hline $10: 01: 02$ & Product ID: 21 & Check marking \\
\hline $10: 01: 06$ & Product ID: 35 & Check is not required \\
\hline $10: 01: 06$ & Product ID: 30 & Check is not required \\
\hline $10: 01: 10$ & Product ID: 45 & Check is not required \\
\hline
\end{tabular}

Figure 7. Displaying system messages during movement.

The figures show the work of the algorithm for predicting and preventing extraordinary situations. For example, if you take the product number 21, then during the move it can be noticed that on arrival in the rack 1 the reader identified only one marking (barcode number: 2055596). After receipt of the product at the place of shipment, the same marking is observed, resulting in the generation of a message and notification of a possible violation in the marking of the product for the purpose of checking it. An example of a general simulation result report is shown in Figure 7:

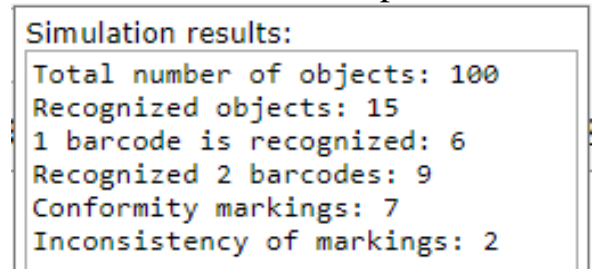

Figure 7. Example of a general simulation results report.

\section{Conclusion}

On the basis of the work done, it can be concluded that when using several labels for product identification, the probability of recognition increases, since regardless of positioning in any case, 1 mark will be visible to the reader. Based on the results of the input data, an imitation of the operating model was developed using the algorithm for predicting and preventing extraordinary situations. The results of simulation have shown effective use for business and implementation in the enterprise.

\section{References}

[1] Parikh D and Jancke G 2008 Localization and segmentation of a 2D high capacity color barcode Proceeding of IEEE Workshop on Applications of Computer Vision 1-6

[2] Astafiev A V, Orlov A A and Popov D P 2017 Development the algorithm of positioning industrial wares in-plant based on radio frequency identification for the products tracking systems CEUR Workshop Proceeding 1901 23-27 
[3] Astafiev A V, Orlov A A and Privezencev D G 2016 Method of controlling the movement of large metal products with the use of algorithms for localization and recognition of bar code markings Dynamics of Systems, Mechanisms and Machines, Dynamics $\mathbf{7 8 1 9 0 4 6}$ DOI: 10.1109/Dynamics.2016.7818969

[4] Orlov A A, Provotorov A V and Astafiev A V 2016 Methods and algorithms of automated twostage visual recognition of metal-rolling billets Automation and Remote Control 1099-1105 DOI: $10.1134 /$ S000511791606014X

[5] Zhiznyakov A L, Privezentsev D G and Zakharov A A 2015 Using fractal features of digital images for the detection of surface defects Pattern Recognition and Image Analysis 25(1) $122-131$

[6] Nhat D D 2015 Researches and application of RFID technology (radio frequency identification) International Research Journal 5 34-37

[7] Kamozin D Y 2013 Comparison of the effectiveness of bar-code technology and RFID technology's application in logistics processes Bulletin of Baikal State University 3 71-75

[8] Kazanskiy N L and Popov S B 2012 The distributed vision system of the registration of the railway train Computer Optics 36(3) 419-428

[9] Morozov A A and Sushkova O S 2016 Analysis of real-time video images using the means of the Actor Prologue Computer Optics 40(6) 947-957 DOI: 10.18287 / 2412-6179-2016-40-6947-957

[10] Epifantsev B N, Pyatkov A A and Kopeikin S A 2016 Multisensory systems for monitoring restricted areas: the capabilities of a video analytics channel for intrusion detection Computer Optics 40(1) 121-129 DOI: 10.18287/2412-6179-2016-40-1-121-129 